\title{
UN CAÑÓN DE CRISTOBAL FRISLEVA EN \\ EL MUSEO NAVAL DE MADRID
}

\author{
POR \\ FRANCISCO JAVIER LÓPEZ MARTÍN
}

\section{RESUMEN - ABSTRACT}

Estudio comparativo entre un pequeño cañón, inédito, conservado actualmente en el Museo Naval de Madrid, firmado por Cristóbal Frisleva y fechado en 1557 y otro cañón del mismo autor depositado en el Museo del Ejército de Madrid, fechado en 1565. Se hace además un breve acercamiento a la figura de su autor.

Comparative study between an unknown small cannon preserved in the Museo Naval from Madrid, signed by Cristóbal Frisleva and dated in 1557, and another one by the same author, preserved in the Museo del Ejercito from Madrid and dated in 1565. A short biographical note on the author is made.

\section{PALABRAS CLAVE - KEY WORDS}

Armas de fuego. Artillería. Arcabuceros. Cristóbal Frisleva.

Firearm. Artillery. Arcabuceros. Cristóbal Frisleva.

Un año después de que Felipe II recibiese de manos de su padre el Emperador las riendas del poder absoluto, Cristóbal Frisleva forjaba en algún lugar de la Península, un pequeño cañón de artillería ligera, conservado hoy en día en el Museo Naval de Madrid catalogado actualmente con el número de inventario 129 . El cañón es de hierro forjado y está dividido en dos sectores, el primero ochavado piramidal y el segundo troncocónico, abocinado en el brocal $^{\perp}$ (figura 1 ).

El primer cuerpo ochavado lleva en la zona de la recámara y sobre las cinco facetas superiores, una faja de $85 \mathrm{~mm}$. de largo decorada a cincel con motivos vegetales. Los espacios libres existentes entre las hojas lanceoladas están adornados con decoración punteada. En la ochava superior y en la zona de la recámara presenta el oído que, dadas las grandes dimensiones que presenta actualmente, debió inutilizarse. Separando esta faja decorada de otra parte lisa, lleva un filete de anillos paralelos entre sí y perpendiculares al eje del cañón cincelados en las mismas cinco ochavas superiores. Al final de este primer cuerpo lleva dos muñones, uno a cada lado, soldados a calda viva para su sujeción a los apoyos de la cureña. En la ochava superior y flanqueada por los muñones lleva troqueladas las siguientes inscripciones y marcas (figura 2):

1 Museo Naval de Madrid (MNM), $\mathrm{n}^{\circ}$ inv. 129. Longitud total: $1393 \mathrm{~mm}$. Longitud sector ochavado: 635 $\mathrm{mm}$. Longitud sector troncocónico: $758 \mathrm{~mm}$. Calibre: $35 \mathrm{~mm}$. Oído: $11 \mathrm{~mm}$. 


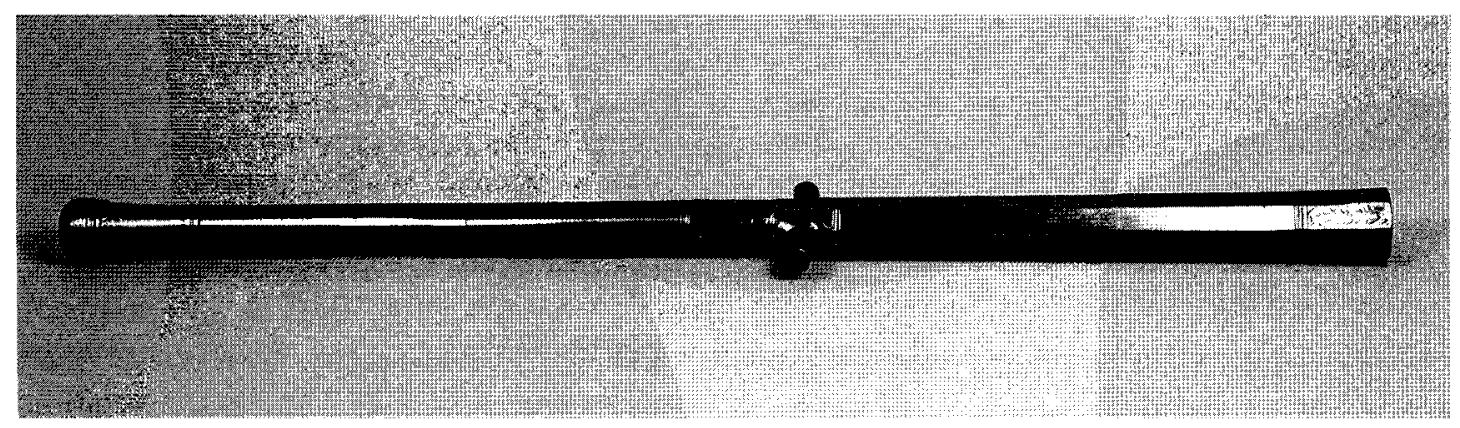

Fig. 1. Cañón n. inventario 129, del Museo Naval (Cañón de 1557).

\author{
X $\quad \mathbf{X}$ \\ 0000000 \\ $G \quad \mathbf{X} F$
$V O C R$
FECITNE
$X P O V A L$
FRSLEVA
$1 \times 5 \times 5 \times 7$ \\ $A N I B A L$
}

El segundo sector, troncocónico, nace igualmente con una faja de la misma longitud que la del primer cuerpo, decorada con los mismos motivos, realizados con igual técnica. Dicha faja está delimitada nuevamente por dos grupos de anillos perpendiculares al eje del cañón uno de los cuales hace la transición hacia una nueva parte lisa, en cuya zona superior cercana al brocal, lleva troquelado el número $494^{2}$. A $145 \mathrm{~mm}$. de la boca de fuego nace otra faja exactamente igual a las dos anteriores pero con la decoración dispuesta en sentido contrario a éstas, abocinándose progresivamente su extremo para enlazar con el brocal, del que está separado por otro filete de anillos más anchos que dan paso a una meseta cincelada con motivos geométricos, donde se encuentra el alojamiento para el punto de mira. Le falta éste último y el cascabel, quedando al descubierto el cierre de culata.

La primera referencia al cañón se encuentra en el catálogo que editó el Museo Naval en el año 1853, donde figuraba bajo el número 281 de esta forma: «Cañón hallado al abrir los cimientos para edificar el obrador de instrumentos naúticos en el Arsenal de Cartagena» ${ }^{3}$, sin dar más explicaciones al respecto y sin precisar la fecha en la que se realizó la obra. Si se ven con detenimiento todas las referencias existentes en los catálogos que aluden al cañón, se observa que esta información original se pierde en el editado en 1934 por otra que dice escuetamente «Sacre o cañón pequeño, fechado en 1557, encontrado en la excavación del dique de Cartagena», cosa que poco o nada tiene que ver con la anotación de 1853 referente

2 Correspondiente al número de inventario bajo el que figura la pieza en el catálogo de 1908. Catálogo del Museo Naval. Madrid, 1908; pág. 55.

3 Catálogo descriptivo de los objetos que contiene el Museo Naval. Madrid, 1853; pág. 55. El Obrador de Instrumentos Naúticos era el establecimiento o instalaciones donde se construían y reparaban los aparatos necesarios para la navegación marítima. Cada Arsenal contaba con un Obrador. 


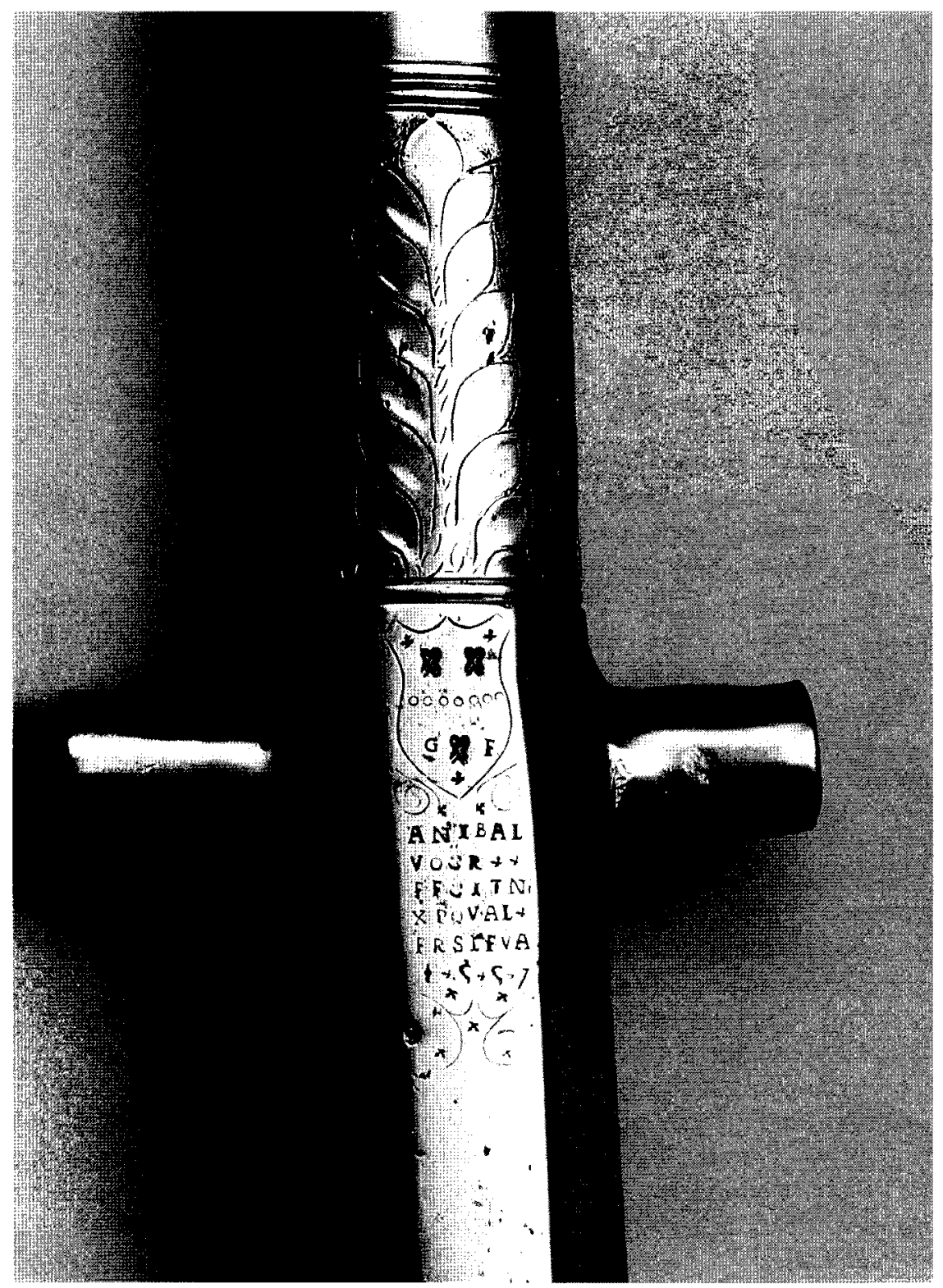

Fig. 2. Vista de la zona central del cañón del Museo Naval. N. ${ }^{\circ}$ Inventario 129 (Cañón de 1557).

a su descubrimiento durante la construcción del Obrador. En el catálogo de 1945 este error quedó definitivamente asentado al figurar como: «Cañón encontrado al abrir el dique». El catálogo del actual Director, Almirante D. José Ignacio González-Aller Hierro volvió, acertadamente, a la noticia de $1853^{4}$.

Además de esta confusión entre los distintos catálogos, se desconocía la fecha del ingreso de la pieza en las colecciones del Museo Naval de Madrid. La primera cuestión planteada fue

4 Catálogo - Guía del Museo Naval de Madrid. Madrid, 1996; pág. 50. 
intentar acotar cronológicamente la edificación del Obrador e intentar, por lo tanto, precisar la aparición del cañón que se expone hoy en día en las colecciones permanentes del Museo.

Pese a que la búsqueda de información que trate parcial o plenamente las obras de construcción del Obrador ha resultado del todo infructuosa, hay dos hechos que delimitan el período de su construcción a prácticamente los siete últimos años del siglo XVIII. El primero de ellos es un plano conservado Museo Naval de Madrid y fechado el 8 de diciembre de 1792, en el que se representa el edificio proyectado para la creación de los Instrumentos Naúticos ${ }^{5}$. El segundo consiste en la primera relación de operarios trabajando ya «oficialmente» en el Obrador con fecha de noviembre de $1799^{6}$. Por lo tanto, la aparición del cañón al excavar los cimientos del edificio se tuvo que producir entre esas dos fechas.

Sea como fuere y si todas estas suposiciones fueran correctas, el cañón tuvo que llegar a Madrid antes de 1853 procedente del Departamento de Cartagena ya que como se ha visto, figura en el catálogo editado ese mismo año. En los archivos del Museo, se encontró una relación de objetos enviados desde Cartagena a Madrid fechada el 3 de mayo de 1845. Esta fecha es importante ya que se sitúa en los orígenes mismos del Museo Naval. A pesar de que el Decreto de creación del Museo se firmó el 28 de septiembre de 1792, no fue sino cincuenta años después, en 1842, cuando se presentó un proyecto de actualización. Esta nueva reforma preveía crear tres secciones o apartados como nervios vitales y fundamentales dentro de la nueva institución, cuyas colecciones irían aumentando (como así ha sido) para prestigio de la Institución, de la Marina Española y del propio Estado, a imagen y semejanza de las demás naciones europeas. Así pues, se contemplaba una primera sección para «bibliotecas de obras memoriales e inventos, tanto nacionales como extranjeras»; una segunda para «modelos de arsenales, astilleros y edificios, además de buques»; y, por último pero no menos importante, una tercera sección «de modelos de artillería y proyectiles con cuanto sea concerniente a este ramo, como igualmente las armas, máquinas de defensa que sean dignas de observarse, tanto por su invención como por haber pertenecido a acciones de guerra que por su particularidad y circunstancias merezcan conservarse»?.

Siguiendo esta política se enviaron cartas destinadas a todos los departamentos navales que la Marina de Guerra tenía repartidos por la geografía española, con el fin de saber qué piezas de las señaladas dentro de los tres grupos anteriores, existían en los departamentos y fuesen factibles de trasladarse a Madrid para conformar el gérmen de la colección del incipiente Museo. El informe, fechado en Madrid el 9 de diciembre de 1843, no deja dudas al respecto: «Estado de los objetos que preferentemente necesita adquirir el Museo Naval en concepto de la Dirección de dicho establecimiento»8; dentro de la sección de armas se deseaban: «modelos de cañones y montajes maritimos de todas clases antiguos y modernos».

5 «Plano que manifiesta un edificio que se propone fabricar en este Arsenal de Cartagena con el frente general al oeste en dos pisos para los obradores de Armería e Instrumentos Naúticos; Cartagena 8 de diciembre de $1792 »$. MNM, Dibujos, P4-18.

6 «Relacion de los individuos con que se hallan dotados los Obradores que tengo á mis ordenes en esta fhâ; Real Arsenal de Cartagena, 11 de Noviembre de 1799». Viso del Marqués, Sección: Arsenales-CorrespondenciaSubinspección, legajo 3666. A pesar de la existencia de una Real Orden, con fecha de 24 de febrero de 1792, por la que se crea el Establecimiento de Obrador de Instrumentos, algunos son de la opinión de que el Obrador no llegó nunca a construirse y que se aprovechó otro edificio ya construido con anterioridad para albergar a los operarios. Según los Estados Generales de la Armada en el período 1788-1792 había dos personas trabajando en el arreglo de instrumentos naúticos. En 1794 aumentó el número a catorce y al año siguiente a veintinueve. Durante los años 1797 y 1798 se alcanzó la cifra de treinta y cinco personas trabajando a la vez. A título comparativo, el Arsenal de Cádiz alcanzó su cenit en 1799 con sólo veinte operarios. Este aumento gradual de la plantilla del Obrador en más de treinta personas a partir de 1794, justifica con creces la construcción de un edificio propio para sus labores.

7 Proyecto para formar un Museo Naval Militar; Madrid, 7 de septiembre de 1842. MNM, Asuntos Particulares, Legajos 1797-1850.

8 MNM, Asuntos Particulares; legajos, 1797-1850. 
Por supuesto que las atenciones principales de Madrid se centraron en los tres lugares fundamentales para la Marina: los Arsenales de El Ferrol, Cádiz y Cartagena.

Este último departamento envió a finales de 1843 un inventario de las piezas que se encontraban depositadas en su almacén ${ }^{9}$. Para el ramo de artillería se adjuntaba un pequeño informe relativo a las armas de fuego y proyectiles antiguos almacenados, expresando en él los calibres y las dimensiones de las piezas y se acompañaba además, de una tabla referente a cuatro trabucos, dos de ellos inservibles, y a un cañón. Las medidas del cañón se dieron en pies, pulgadas y líneas ${ }^{10}$. Pero lo más importante es que la tabla iba acompañada de dos notas. La segunda hace referencia a los trabucos citados; la primera dice textualmente: «El cañón que se espresa en este Estado no es posible saber su procedencia pues fue encontrado en las Escabaciones que se hicieron para formar el Obrador de Instrumentos Nauticos». Esta es, sin lugar a dudas, la primera referencia escrita del cañón de Cristóbal Frisleva desde su aparición en Cartagena, y es además el origen y la causa de todas y cada una de las anotaciones posteriores que se han publicado hasta la fecha. A la hora de elaborar el pequeño informe se tuvo especial cuidado en realizar las mediciones, abundantes para la fecha en la que fueron tomadas, y que, comparándolas actualmente, sirven de forma inigualable para asegurar la afirmación de que se trata del mismo cañón, ya que coinciden plenamente con las tomadas actualmente a la pieza. Nótese también que en las mediciones de los diámetros se señala oportunamente el segundo cuerpo como «achaflanado», es decir, cortado en planos por las aristas; esto es, ochavado o facetado; otra característica más para confirmar que se trata sin lugar a dudas del cañón. Si bien la anterior ubicación que esta pieza de artillería ligera tenía en el puerto de Cartagena se desconoce, ya que se encontraba enterrada, sí que queda confirmada de esta forma su aparición durante las excavaciones de un edificio, que según esta nota, tomada en el mismo lugar del suceso, se trataba del Obrador de Instrumentos Naúticos del Arsenal.

Anteriormente se ha visto cómo siguiendo esa política de búsqueda y recolecta de piezas interesantes para las colecciones propias de un museo naval, se enviaron desde diferentes centros de la Marina diversos inventarios. Una vez vistos y seleccionadas de ellos las piezas, trabajo ímprobo por la cantidad de los fondos reseñados, faltaba únicamente enviarlas a Madrid.

Prácticamente un año y medio después de la recepción en Madrid del inventario de Cartagena, se enviaron diversas cajas repletas de los objetos que hoy mismo se pueden seguir admirando en las vitrinas del Museo, convertidos ya en obras de arte. Una de esas cajas, enviada en mayo de 1845 , contenía diecisiete piezas, entre ellas «un cañon de fierro con muñones antiguo, sin montage» ${ }^{11}$. Esta escueta nota, a pesar de carecer de datos inequívocos que demuestren que se trata indudablemente del cañón objeto de este estudio, parece claro que sí se refiere al de Cristóbal Frisleva, ya que no aparecen en las relaciones existentes otros cañones de hierro, «antiguos» y sin cureña, que procedan de Cartagena y fuesen enviados a Madrid por aquellas fechas con los que pudiera llegar a confundirse. Es cierto que en otra relación de piezas llegadas desde Cartagena con posterioridad a este primer envío, aparecen

9 Relacion de los modelos de Buques, Edificios, Maquinas, armas de fuego, Proyectiles antiguos que existen en este Arsenal y son Correspondientes a los Ramos que acontinuacion se expresan. Comandancia y SubInspeccion del Arsenal Nacional de Cartagena. Madrid, 2 de noviembre de 1843. MNM, Asuntos Particulares, Año 1842.

10 «Longitud total: 5 pies, 9 lineas. Diámetro exterior del ler. cuerpo: 2 pulgadas, 3 lineas. Id. del $2^{\circ}$ achaflanado: 2 pulgadas, 9 lineas. Id. del Anima: 1 pulgada, 3 lineas. Espesor del ler. cuerpo: 6 lineas. Id. del $2^{\circ}$ cuerpo: 11 pulgadas, 3 lineas. Diámetro de los muñones: 1 pulgada, 4 lineas. Id. del oído: 6 lineas».

11 «Relacion de los efectos que se han entregado en este dia a Fulgencio Saura mayoral de galera corsaria de la carrera de Madrid, para conducir a dicha villa y entregar en el Museo Naval de la Corte, según Real Orden»; Cartagena, 3 de mayo de 1845. MNM, Asuntos Particulares, legajos 1797-1850. Originales conservados actualmente en el Archivo General de la Administración, en Alcalá de Henares. 
registrados otros cañones, aunque se dice claramente que uno de ellos es de bronce, y otro es de madera y montado sobre cureña, con lo que las posibles dudas quedan despejadas.

Debido al éxito alcanzado, el Museo tuvo que mudarse a principios de 1844 a la llamada Casa del Platero, en la madrileña calle Bailén. Fue entonces cuando se creyó conveniente, debido al incremento de los fondos, hacer un inventario de las propias piezas ya integradas en el Museo.

Actualmente existen en los archivos del Museo Naval dos copias manuscritas de este inventario, fechadas en Madrid el mismo día, 30 de abril de 1847. En este inventario, en la Sección Tercera y con el número 66, figura el cañón con la siguiente anotación al margen: «Cañón hallado al abrir los cimientos para edificar el obrador de instrumentos naúticos en el Arsenal de Cartagena» ${ }^{12}$, reseña que se produce tan sólo cuatro años después de que llegue el inventario de Cartagena, del que indudablemente tomó la información. Todos los catálogos posteriores se limitaron a copiar literalmente ésta frase, sin intentar averiguar nada más al respecto e investigar en los papeles custodiados en el propio Museo, con la salvedad de los editados en 1934 y 1945, que ni siquiera llegaron a copiarla acertadamente.

Anteriormente a todos estos datos, se tenía documentada la aparición más antigua del cañoncito en el Museo en 1853, fecha que, como se ha visto, corresponde a la publicación de su primer catálogo, pero resulta evidente que hay que retrotraer su aparición por lo menos cerca de nueve años antes.

Por qué motivo el cañón apareció en Cartagena es una cuestión que probablemente nunca se dilucidará ${ }^{13}$, pero hay que tener presente que el Arsenal era una de las bases más importantes de la Escuadra de Galeras del Mediterráneo precisamente desde el siglo XVI, así como un importante puerto, junto con Barcelona, desde el que se enlazaba con el resto de las ciudades del ámbito mediterráneo.

Encontrar hoy en día dos piezas semejantes salidas de la mano de un mismo autor es francamente difícil, excepto en el caso de que sean parejas realizadas con tal propósito por el autor.

El encontrar dos piezas de artillería ligera realizadas en hierro forjado, salidas de la misma mano que empuñaba el martillo junto al calor de la fragua y prácticamente iguales, es un hecho insólito. Si además ambas piezas están firmadas y fechadas el caso se convierte en extraordinario.

Pero esto es precisamente lo que ocurre con el cañón forjado por Cristóbal Frisleva durante el año 1557.

\section{EL CAÑON DE 1565}

El 27 de enero de 1911, después de la reorganización que sufrió la Real Armería de Madrid, un pequeño grupo de cañones fueron trasladados en calidad de depósito temporal al Museo de Artillería, actual Museo del Ejército, situado también en la capital. Concretamente formaban un total de 29 piezas en hierro y bronce, que intentaban dar una imagen de la artillería española comprendida entre los siglos XVI y XIX. A cambio, el Museo de Artillería cedió para su custodia en Palacio diferentes partes de armaduras. Por parte de la Armería

12 Inventario General; Sección Tercera, artillería y subinspección; Madrid, 1847.

13 A pesar del hecho innegable hasta ahora de que el cañón se encontrase enterrrado hasta su aparición en las cercanías del mar, hay que decir que el estado de conservación anterior a la restauración efectuada entre los meses de marzo y mayo de 1998, no presentaba signos de haber estado sometido a unas condiciones altas de humedad, propias de un ambiente cercano al litoral marino, ni siquiera alteraciones más o menos importantes a base de escoriaciones, propias de los ataques de depósitos de óxido. Únicamente presentaba una capa oxidativa no uniforme, pardo-rojiza, propia de una alteración rápida y estéticamente fea. Actualmente la pieza se halla en un estado de conservación excelente y no muestra signos de inestabilidad originados por fenómenos de corrosión. 
firmó su conservador don José María Florit y por el Museo, el Coronel de Artillería don Teodoro de Ugarte ${ }^{14}$. La primera pieza que aparece en la relación de los fondos que intercambiaron ambas instituciones es un «Cañón de acero con afuste siglo XVI, firmado de Freisleva», cita que recuerda por lo escueto, a la nota manuscrita de la relación de Cartagena de 1845 . Este intercambio quedó prontamente reflejado en el nuevo catálogo del Museo de Artillería que se empezó a editar ese mismo año (el mejor catálogo publicado hasta la fecha de sus colecciones), donde ya figuraba el cañón bajo el número $4627^{15}$, número de inventario que todavía hoy conserva.

La primera referencia publicada que alude a él, aparece en el inventario de la Real Armería de 1793 donde en el apartado de armas de fuego se dice: «Un cañón de hierro batido con calibre de una pulgada y dos lineas, hecho en el año de 1565 , reynando D. Felipe II «16.

En el catálogo de Martínez del Romero aparece reflejado bajo el número 231917, y con igual leyenda y la misma numeración, en el de $1861^{18}$. Sin embargo, en el realizado en 1898 por don Juan Bautista Crooke y Navarrot, Conde Viudo de Valencia de Don Juan, no aparece reseñado ya que este último catálogo no hizo referencia a la artillería, esperando la aparición de un apéndice que nunca vió la luz.

De esta forma el cañón pasó en 1911, como se ha visto, al Museo de Artillería, en donde se mantuvo hasta que de nuevo se envió en mayo de 1987 al Museo Regional Militar de Burgos en donde su función fue puramente decorativa. La pieza logró retornar a Madrid en julio de $1996^{19}$.

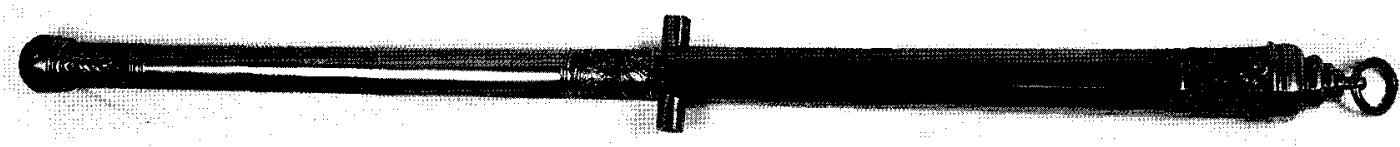

Fig. 3. Cañón N. Inventario 4627 del Museo del Ejército (Cañón de 1565).

Comparando ambos cañones se observa que son casi idénticos salvo por que el ejemplar custodiado actualmente en el Museo del Ejército es ligeramente mayor ${ }^{20}$ y está mejor acabado $^{21}$ (figura 3). La importancia de este hecho es única, puesto que no tiene parangón en el

14 Archivo General de Palacio, Caja 15826, Expediente 26.

15 Catálogo General del Museo de Artillería. Madrid, 1914; tomo IV, pp. 612-614.

16 Resumen sacado del inventario general histórico de los armeses antiguos, armas blancas y de fuego con otros efectos de la Real Armería del Rey Nuestro Señor. Por Ignacio Abadía. Madrid, Imprenta Real, 1793; pág. 33.

17 «Cañon de hierro batido, ochavado en su mitad inferior y montado en una cureña. Tiene un escudo en que se lee IN DOMINO CONFIDO. 1565. CRISTOVAL FRISLEVA ME HIZO; y mas abajo repite: HIZOME EN RICLA CRISTOVAL FRISLEVA AÑO 1565. Calibre 1 pulgada y 3 líneas». Catálogo de los objetos de la Real Armería. Madrid, 1849; pág. 158 del catálogo.

18 Catálogo de los objetos de la Real Armería. Madrid,1861; pág. 142.

19 "Baja en Depósito al Museo Regional Militar de Burgos en fecha 20 de mayo de 1987 según escrito $n^{\circ}$ 182 de fecha 13 de mayo de 1987, de la Secretaría General de este centro». A continuación lleva la anotación manuscrita: "Regresó el 17 de julio de 1996». Catálogo de la Planta de Artillería, $\mathrm{n}^{\circ} 4627$. La orden de entrada del cañón figura en su expediente, bajo el mismo número de inventario.

$20207 \mathrm{~mm}$. más de largo respecto del ejemplar del Museo Naval.

21 Museo del Ejército de Madrid, $\mathrm{n}^{\circ}$ inv. 4627: Longitud total: $1600 \mathrm{~mm}$. Longitud sector ochavado: 690 $\mathrm{mm}$. Longitud sector troncocónico: $730 \mathrm{~mm}$. Longitud cascabel: $110 \mathrm{~mm}$. Calibre: $30 \mathrm{~mm}$. 
mundo de las armas el encontrar dos piezas de un mismo autor en las cuales la primera haya podido servir de modelo para la posterior realización de la segunda. Ambos cañones están divididos en una primera parte ochavada, (o achaflanada, tal y como decía a propósito del cañón del Museo Naval, el inventario de Cartagena de 1843) y otra segunda troncocónica, a partir de los muñones, prácticamente de las mismas dimensiones ${ }^{22}$. Las tres fajas decorativas que presenta el ejemplar del Museo Naval las porta también el del Ejército, de las mismas medidas; y aunque se varió ligeramente la decoración, ésta no deja de ser igualmente vegetal, incluyendo el punteado entre las hojas. No obstante, el autor puso más empeño en mejorar su segunda obra, en perfeccionar el trabajo realizado. Así cuidó hasta el extremo la elaboración manual de su nueva ejecución, armonizando los elementos estructurales (brocal, muñones y la propia caña de la pieza), y los decorativos, con un resultado final en el que se aprecia una terminación más compacta, observándose un cañón más entero, más recio que el ejemplar del Museo Naval. Mejoró y perfeccionó en el dibujo los elementos decorativos realizando unas hojas más lanceoladas, más anchas y robustas; se podría decir más pesadas, manteniendo un trazo más preciso con el cincel. Ensanchó y dió profundidad al brocal dándole una curvatura más pronunciada. Para hacer otra comparación de las similitudes sólo hace falta acudir a la documentación generada por los cañones mismos. Nótese que el calibre que se da en la tabla del inventario de Cartagena para el cañón de 1557 varía solamente en una «línea» (cerca de dos milímetros), respecto al que da el inventario de la Real Armería de 1793 para el de 1565. Esta diferencia tan mínima no se da por casualidad en dos piezas hechas a mano hace casi cuatrocientos cincuenta años. Frisleva, o bien anotó las medidas de su primer cañón, o hizo el segundo, si no con el anterior a la vista, sí con algún dibujo que se lo recordase.

El deseo patente del autor a la hora de mantener el diseño, tanto estructural como artístico de su anterior realización, queda indiscutiblemente demostrado por el hecho de que ni siquiera se molestó en modificar un detalle tan insignificante en el conjunto del arma como son las pequeñas flores, apenas dos ramitas cruzadas, que jalonan y adornan con su compañía, las leyendas de ambos cañones.

Se analizará en primer lugar la leyenda del cañón de $1557^{23}$ (figura 4). Sobre la faceta superior y entre los muñones lleva escrito:

ANIBAL
VOCR
$F E C I T N E$
$X P O V A L$
$F R S L E V A$
$I \times 5 \times 5 \times 7$

Abriendo y cerrando esta inscripción lleva cinceladas sencillas volutas a modo de decoración. Por encima de todo ello lleva un escudete, dentro del cual se inscriben tres aspas, dos en paralelo y la tercera más abajo y en medio de las otras dos, flanqueada esta última por las letras $G$ a su izquierda y $F$ a su derecha, separándose ambos grupos por una hilera de siete círculos que atraviesan el escudo de lado a lado y lo dividen en dos:

22 Lo que cada cañón gana respecto al otro en uno de los dos sectores de la caña, lo pierde en el otro.

23 Hay que señalar el hecho de que con anterioridad a la edición del Catálogo-Guía realizado por el director del Museo Naval (1996), en ninguna parte figuran recogidas las inscripciones en su totalidad. En la transcripción de la leyenda recogida en dicho Catálogo-Guía se incluyeron dos $\mathrm{X}$, cuando en realidad se trata de flores ornamentales; la única $\mathrm{X}$ es la perteneciente al nombre propio del autor. 


\section{$\mathbf{X} \mathbf{X}$ \\ 0000000}

$G \quad \mathbf{X} F$

Las dos primeras palabras de la inscripción, ANIBAL VOCR, están escritas en latín y forman una sola frase. Puesto que Aníbal es un nombre propio y no admite confusión como sujeto sintáctico, la palabra Vocr debe ser la abreviación de un verbo. Parece claro que se trata del verbo Vocatur (del verbo Voco); aunque también pudiera tratarse de una inscripción «parlante», comunes desde la más remota antiguedad, en cuyo caso sería la abreviación de Vocor. El hecho de que la palabra Aníbal conste de seis letras y Vocor de cinco, hace pensar

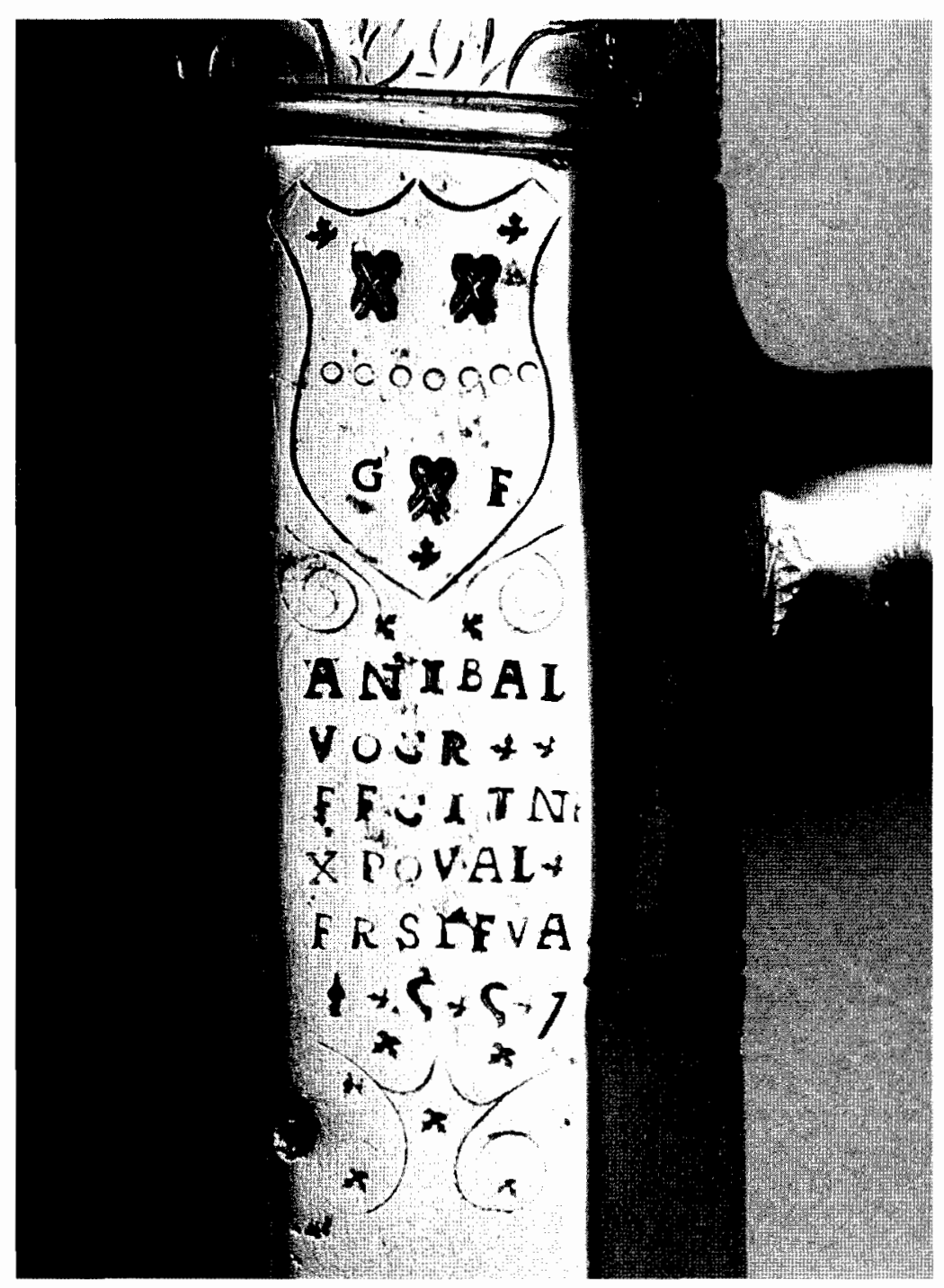

Fig. 4. Detalle de la leyenda entre los muñones.

Cañón N. ${ }^{\circ}$ Inventario 129 (Cañón de 1557). 
que puesto que la primera cabe perfectamente en su línea (manteniendo los márgenes y el debido espacio entre las letras), la segunda no tenía por qué haberse abreviado, más aún cuando a continuación, en los dos espacios libres que restan, se estamparon sendas florecillas para cerrar la línea y alinear el margen. No obstante, Vocatur se traduciría por ES LLAMADO y Vocor por ME LLAMO, o SOY LLAMADO. Por lo tanto, aunque el hecho de estar el verbo abreviado lleve a pensar más en la opción de Vocatur, la traducción concuerda mejor con la siguiente palabra mediante la opción de Vocor, esto es: ME LLAMO ANIBAL. También es de señalar, aunque no modifique en absoluto su sentido, el hecho de que la palabra Anibal se escribió completamente castellanizada, ya que en latín se escribe con $H$ inicial y doble $n$ (Hannibal); no obstante a su relativa importancia habrá que tenerlo en cuenta más adelante ${ }^{24}$.

El tercer renglón presenta FECIT NE que si bien no plantea dudas sobre su traducción, sí que hay que observar el que en lugar de una letra $M$ haya una $N$. Fácilmente se nota también el hecho de que si Vocatur se abrevió por su longitud, una sencilla cuenta para fecit me nos da como resultado el mismo número de letras, sin separarlas con un espacio, y sin embargo se estampó a sabiendas de que no cabía, como puede apreciarse sobre el cañón, donde la $E$ está constreñida entre la $N$ y el borde de la faceta.

El cuarto renglón lleva escrito X $P O V A L$. Esta es la abreviatura del nombre Cristóbal cuyo origen hay que buscarlo en el crismón, el anagrama que representaba a Cristo entre los primeros cristianos, quienes lo utilizaban como una contraseña para pasar inadvertidos en la Roma Imperial. Su escritura proviene de las letras griegas $j i(\mathrm{X})$ y la ro $(\mathrm{P})$ y se latinizó como Christvs. De ahí que en muchas inscripciones se encuentre la abreviatura XPS para referirse a Jesucristo (Cristós, del griego Jristos). Pasado el tiempo el nombre de Cristóbal se abrevió en la forma Xtóbal, entendiéndose la $X$ inicial por el conjunto Chris. Pero también se utilizó otra forma un poco más compleja. Como el crismón se representaba con una $P$ sobre una $X$, se abrevió también utilizando la $X$ por $c h$ y la $P$ por la $r$. En este caso sería $C H R(I S T) O B A L$ es decir, $X P(I S T) O B A L$, como figura en el cañón. El hecho de que se escriba con $\mathrm{V}$ en lugar de $\mathrm{B}$, no tiene importancia ya que a mediados del siglo XVI la ortografía no estaba completamente definida. En cualquier caso, era una abreviatura corriente en la época ${ }^{25}$.

Por fin, el quinto y último renglón antes de la fecha presenta el apellido del autor, Frisleva, donde el rasgo más notable es la ausencia de una o más vocales al inicio de la palabra, que permitan su lectura correctamente. Se puede añadir que hay estampadas aquí siete letras bien holgadas (FRSLEVA), en el mismo espacio en donde antes no cupieron correctamente (FECITNE).

En definitiva, la leyenda se puede traducir de la siguiente manera:

\section{ME LLAMO ANIBAL. ME HIZO CRISTOBAL FRISLEVA. (Año) 1557.}

24 La figura de Aníbal aparece ya retratada con todo su esplendor en la antiguedad clásica. Autores como Polibio, Livio y Plutarco describieron su carácter e historia de forma ambigua: unos como héroe y otros como el ejemplo de la fragilidad del alma humana. Durante el siglo XVI (y XVII) su figura queda más unida al entusiasmo que despierta su personalidad vinculada a la imagen que del héroe se tiene en el renacimiento: «Y de Hannibal dize Tito Livio que siendo moço militando en el exercito de Asdrubal, dormia de ordinario en el suelo, cubierto con vn repostero de campo, y en su comer y vestir no se diferenciava de los de mas soldados de su cargo. Y lo mismo se refiere de Scipion el Aphricano, y de otros Cavalleros Romanos, que con en esta virtud vinieron á ser excellentisimos Capitanes». Bernardino de Escalante, Diálogos, pág. 78. Igualmente Calvete de Estrella: «... aquel grande Hanibal de Carthago, y Publio Scipion Africano, contendian entre si cada vno, q podian ygualarse en virtudes y belicosos hechos co el Emperador Carlos Quinto Maximo...» El Felicissimo Viaje, pág. 172 r. La grandeza y genial individualidad de Aníbal la resumió perfectamente F. Grillparzer en su Hannibal und Scipio (1835) al decir «Cartago sólo dispone de un Aníbal, mientras Escipión es para Roma uno de tantos»; o M. Greif en su poema Sagunt: "¿no has vertido lágrimas de admiración por él en tu juventud?». Frenzel, E.: Diccionario de Argumentos de la Literatura Universal. 1976; pp. 29 y ss.

25 En muchos testamentos o tasaciones de bienes es fácil encontrar «dos espejos de xptal»; o «copa de xptal». Igualmente un «Xpto de zafiros», etc ... 
Por lo que respecta al escudete, se puede conjeturar como una hipótesis el hecho de que las letras $G$ y $F$ hagan alusión al nombre y apellido del autor, Cristóbal Frisleva; el hecho de que la letra $G$ no coincida con una $C$ de Cristóbal, no debe llamarnos demasiado la atención si se atiende en primer lugar a la mala calidad del conjunto de la leyenda y en segundo lugar, a la confusión ortográfica aludida más arriba, en plena boga a mediados del XVI. Respecto a las tres $X$ marcadas en el interior del escudo no hay ninguna duda de que se trata de la firma emblemática de Frisleva, tal y como nos lo dejó escrito Isidro Soler ${ }^{26}$ y nos lo confirma el cañón de 1565. Las cinco X marcadas por Frisleva con las que se cuenta en la actualidad, tres en un cañón y dos en el otro, son exactamente iguales, con un relieve claro y bien estampado que resalta en su interior. El pensar que Frisleva adoptó por firma emblemática una letra X por ser la abreviatura normal en su época de su propio nombre Chris, de Cristóbal, es algo que sin estar demostrado, bien pudiera tener algo de cierto. En cualquier caso, la X marcada se puede tomar con absoluta seguridad por la «contramarca» del autor, es decir, su identificación emblemática; quizás las letras G y F se estamparon con la intención de reflejar la «marca», esto es, la abreviatura del nombre, aunque el cañón de 1565 no las lleve, si bien es cierto que ambos cañones llevan el nombre y apellido completos del autor, en clara contradicción con las últimas teorías ${ }^{27}$ y más acorde en cambio, con las leyendas propias de una pieza de artillería.

En definitiva, lo que se quiere probar con este pequeño análisis paleográfico es la mala calidad de la leyenda estampada en el cañón de 1557. Las letras y números de la inscripción fueron marcados individualmente, mediante un sistema de tipos móviles, como en una imprenta, con el cual, el maestro o la persona que troqueló la leyenda fue estampando uno a uno cada carácter, en lugar de confeccionar previamente a la estampación una «cartela» con cada palabra. Esto queda claramente reflejado en la estampación de la fecha, donde se observa una caída hacia el lado derecho, que no se produciría si se hubiera estampado de una sola vez. La mano que estampó la inscripción se cuidó tan poco de ésta, que incluso al empezar a marcarla se equivocó de palabra, empezando por la segunda (VOCR), como lo demuestra la letra $\mathrm{V}$ marcada con anterioridad a la letra $\mathrm{A}$, tal y como se puede apreciar con detenimiento. Esta leyenda pasaría perfectamente un examen de caligrafía si no fuese por que hay otra con la que compararla, marcada por el mismo autor tan solo ocho años después.

La leyenda del cañón de 1565 es la siguiente. En un escudete colocado en la mitad del cañón se puede leer (figura 5):

\section{YNDOMINO \\ CONFIDO \\ $15 \times 65$ \\ CRISTOVAL \\ FREISLEVA \\ $M E H I 3$

26 «Christoval de Ricla, que ha sido fabricante en Aragon, y ponía por marca una X». Soler, I.: Compendio Histórico de los Arcabuceros de Madrid. p. 42.

27 Lavin indica que hacia final de siglo los maestros de cañones de arcabuces empezaron a marcar sus nombres completos, como hizo Leguisamón en 1596 o Juan Salado a principios del siglo XVII. Respecto a Frisleva señala que «During the sixteenth century, gunsmiths such as the Marquarts and Cristóbal Frisleva used simple marks, and their exalted reputation made further identification unnecessary». Lavin, J. D.: A History of Spanish Firearms, pág. 213. 
Y cincelado sobre la zona de recámara (figura 6):

$$
\begin{aligned}
& \text { HI3OME EN } \\
& \text { RICLA } \\
& \text { CRISTOVAL } \\
& \text { FR ISLEVA } \\
& A \tilde{N} O \\
& 1565 \\
& \mathrm{X}
\end{aligned}
$$

James D. Lavin trató por vez primera el cañón de $1565^{28}$, limitándose únicamente a una descripción somera ya que sus objetivos iban mucho más allá que al estudio pormenorizado de esta pieza. A pesar de ello, reflejo la leyenda en su totalidad.

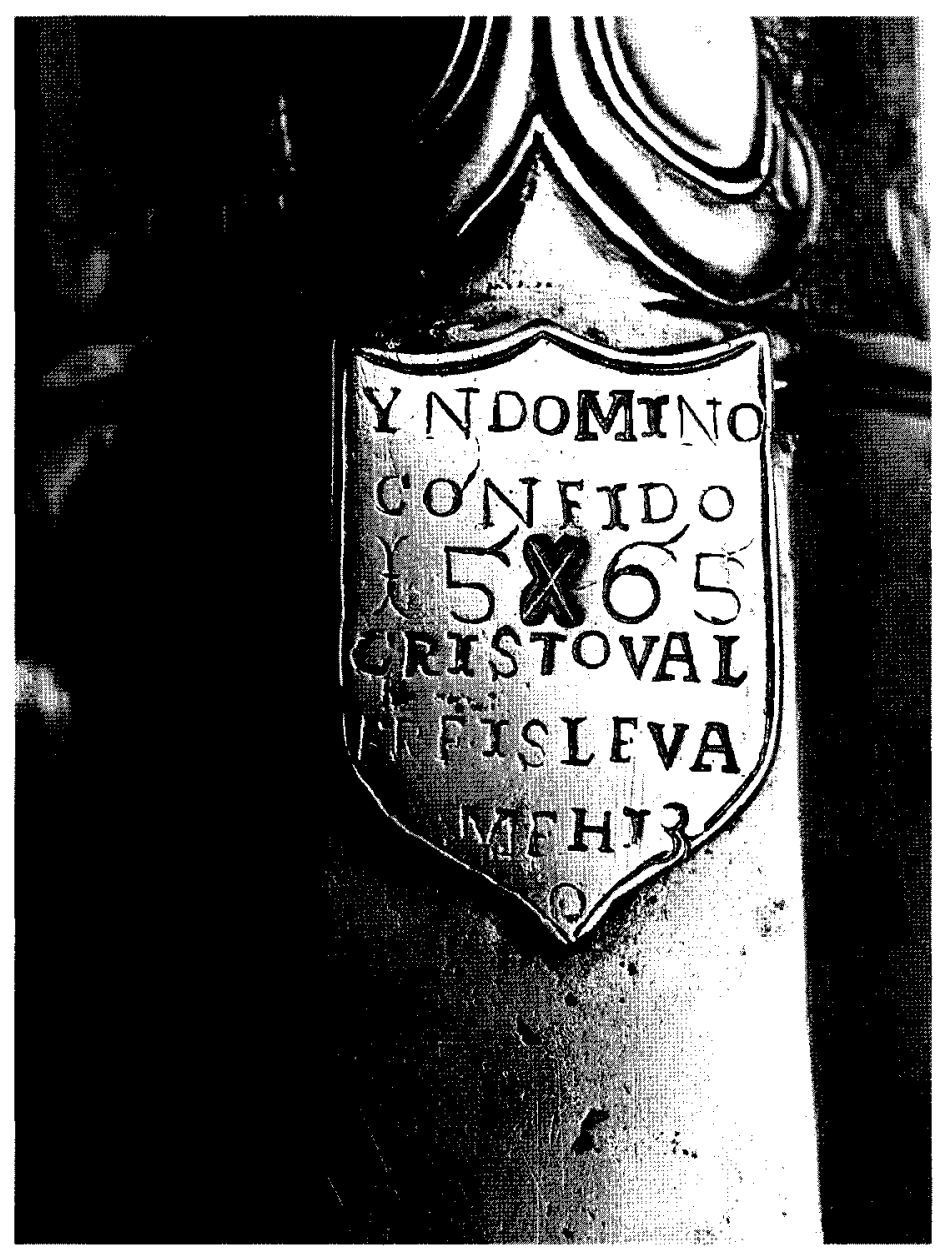

Fig. 5. Detalle del escudete entre los muñones. Cañón N. ${ }^{\circ}$ Inventario 4627 (Cañón de 1565). 
Como se puede apreciar, las semejanzas entre una y otra leyendas son grandes, si no tanto en las inscripciones, sí en el modo de confeccionarlas. Ambas muestran sendos escudetes colocados entre los muñones, si bien el ejemplar de 1557 lo lleva cincelado y en el realizado ocho años más tarde se modeló primeramente para soldarlo después a calda viva directamente sobre el hierro candente del cañón. Debajo de los escudetes, el autor situó la firma y el año de fabricación, adornadas ambas con la pequeñas flores. Sin embargo, hay unas diferencias notables entre una y otra. En primer lugar, en la leyenda de 1565 el autor no olvidó estampar las letras con una ortografía que mejoraba ostensiblemente su escritura anterior, no faltando (como en su apellido) ni confundiendo (como en «FECITNE») ninguna letra. En segundo lugar hay que señalar que la leyenda está escrita casi enteramente en castellano (con la salvedad del Confío en el Señor), con el nombre completo del autor y dejándo bien claro el topónimo donde se realizó la obra: en Ricla, en las cercanías de Zaragoza. Por el contrario, el ejemplar de 1557 carece de cualquier alusión geográfica en donde se labrara el cañón. Por último, pero no por eso menos importante, el cañón de 1565 no está «bautizado» a diferencia, como se ha visto, del «Aníbal».

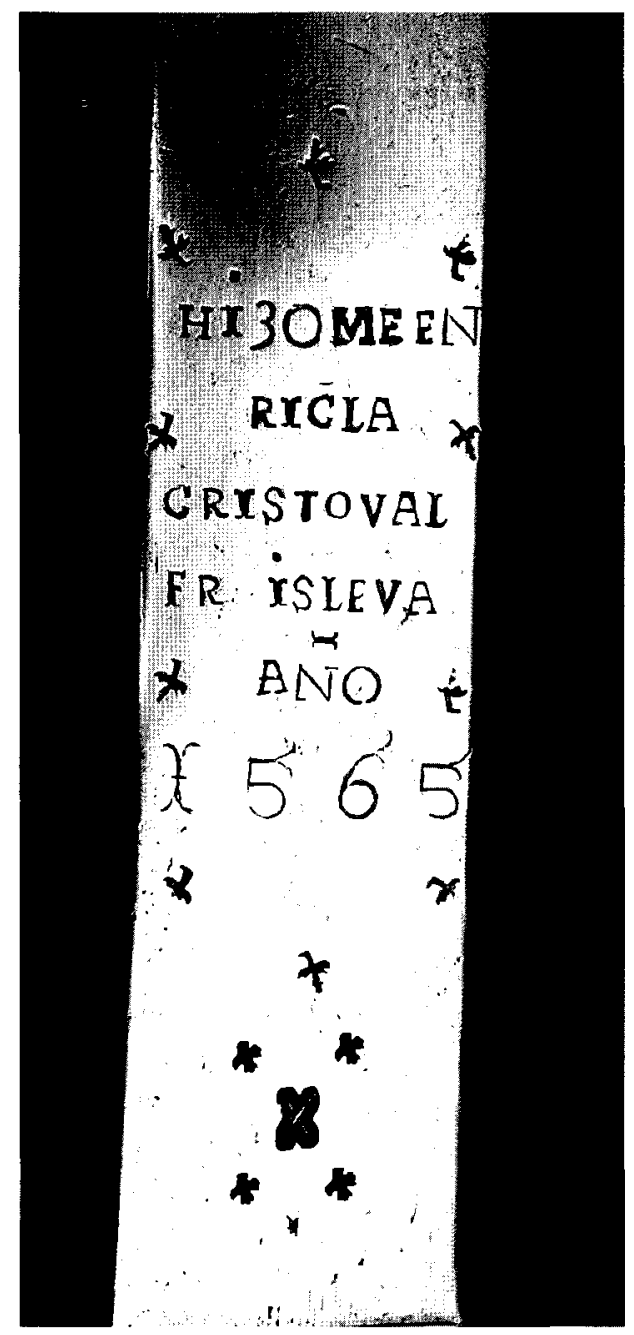

Fig. 6. Detalle de la leyenda sobre la recamara. Cañón N..$^{\circ}$ Inventario 4627 (Cañón de 1565). 
El ejemplar de 1565 sigue conservando hoy en día el punto de mira y el cascabel (figura 7), al contrario que el de 1557, que debió perderlos por accidente, ya que conserva el alojamiento para engastar el punto. Puesto que el cañón fechado más tarde se hizo a imagen y semejanza del primero, cabe suponer que también ambos elementos fueran muy similares, si no iguales, de forma que sirven inmejorablemente para conformar actualmente una idea de ellos. Para reafirmar esta teoría hay que señalar que las medidas del alojamiento donde iba colocado el punto en el cañón de 1557 son las mismas que en el de 1565. Así mismo, las medidas del bloque de culata de uno y otro también coinciden.

Por último queda mencionar dos hechos que no pasan desapercibidos, ambos en el cañón de 1565. El primero de ellos se basa en que este cañón, mejor acabado en todos los aspectos, se encuentra sin desbastar en la parte inferior de su mitad ochavada, a diferencia del ejemplar de 1557 que sí lo está. El segundo ejemplar está montado sobre una cureña que está asociada al cañón por lo menos desde $1793^{29}$, sin que se sepa con certeza si es contemporánea al cañón o bien una realización posterior hecha en el siglo XVIII. Sin embargo no deja de resultar curioso que esta parte inferior, precisamente la oculta por la madera, no requiriera las molestias de Frisleva en su acabado final, como si el cañón se hubiese realizado conociendo previamente su futuro encabalgamiento a un montaje.

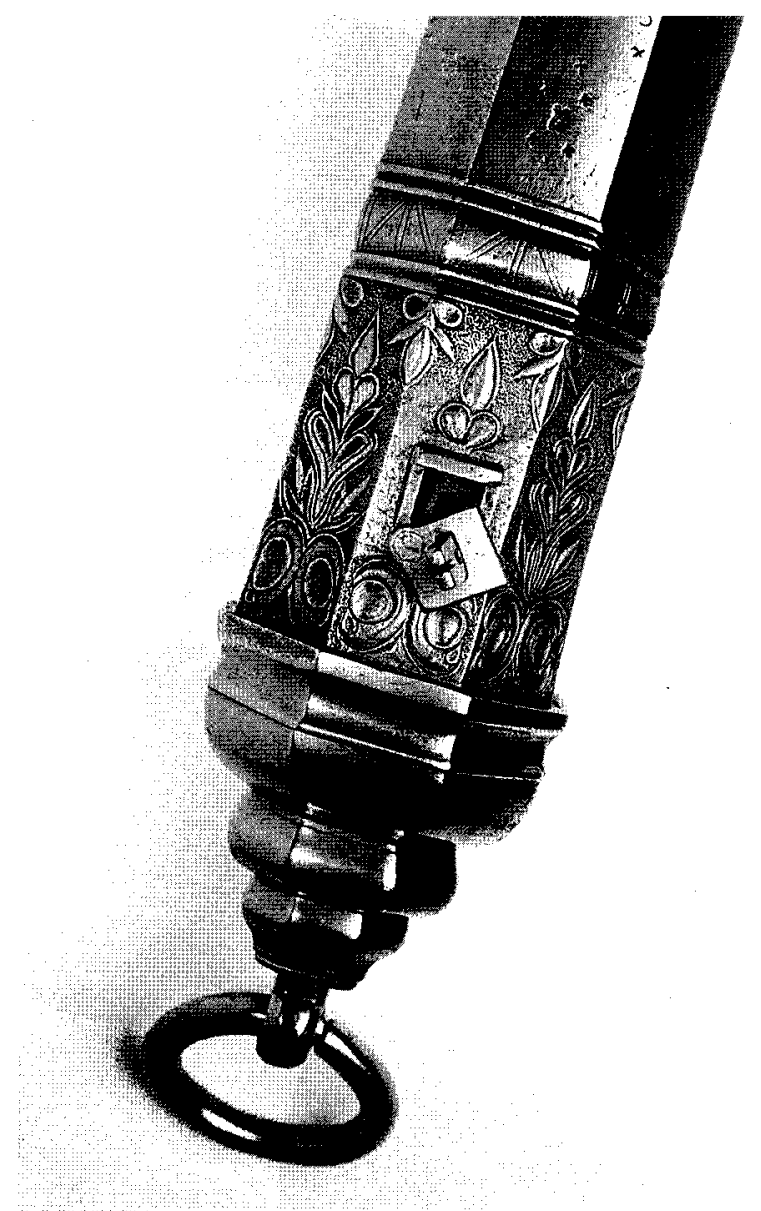

29 Inventario de la Real Armería de Ignacio Abadía, pág. 32.
Fig. 7. Detalle de la zona de recamara del cañón. $\mathrm{N}^{\circ}$ inventario 4627. Se aprecian la tapa de la cazoleta girada y el cascarel rematado en anilla. 
El segundo hecho se fundamenta en que este mismo ejemplar porta sobre el oído un receptáculo cuadrangular a modo de cazoleta para proteger la pólvora depositada en él, con la que se daba fuego a la pieza en el momento del disparo. Unido al receptáculo mediante un eje, lleva una tapa o cobija que permite su apertura o cierre a voluntad. Encima de esta tapa se situó una pieza con forma de pirámide truncada cuyo lado superior lleva una escotadura en $\mathrm{V}$ y que además está perforada por un agujero a modo de dioptra. Ambos, escotadura y dioptra, están alineados con el punto situado en el brocal. El hecho de llevar unos instrumentos de puntería tan precisos, fijados a una arma de este tipo a mediados del siglo XVI, no deja de ser insólito para una pieza de artillería, en las cuales los elementos de puntería consisten generalmente en un punto situado en lo más alto de la boca de fuego y una elemental mira, si la llevan, apenas insinuada en la zona de la recámara.

\section{CRISTOBAL FRISLEVA Y LA PRODUCCION DE ARTILLERIA DE HIERRO A MEDIADOS DEL SIGLO XVI}

Ya desde principios del siglo XVI o incluso antes ${ }^{30}$, se fue abandonando paulatinamente la fabricación de artillería de hierro forjado sustituyéndola por la de bronce fundido ${ }^{31}$ debido a las ventajas que ofrecía esta última tanto en la seguridad del disparo, como frente a la corrosión. El hierro era un mineral muy abundante en España y por lo tanto la producción de armas de artillería fabricadas con este mineral era barata en tanto en cuanto la mano de obra no aumentase los costes. El problema de la producción de artillería fundida en bronce no era de tipo técnico, sino económico. Los precios del estaño y sobre todo los del cobre no dejaron de aumentar durante toda la centuria ya que, a diferencia del hierro, no eran metales tan abundantes y por lo tanto la oferta era más rígida y su demanda mayor. ${ }^{32}$ Durante la primera mitad del siglo XVI se observa una alternancia entre la artillería de hierro forjado y la de bronce, si bien la primera se seguía utilizando por diversos motivos. En primer lugar, debido al inferior coste mencionado. En segundo, porque como ocurre también hoy en día, se debía sacar rentabilidad incluso del armamento obsoleto debido a la precariedad de los recursos financieros de la Corona, tanto para el establecimiento de una producción nacional, como para la importación de cañones. Y en tercer lugar, simplemente, porque la producción en bronce no bastaba para las demandas de unos ejércitos cuyo campo de acción llegó a ser, dejando aparte las vastas extensiones a defender del Imperio Ultramarino, toda Europa occidental, desde el Mar del Norte al Mediterráneo ${ }^{33}$.

30 Véase los trabajos de Carrasco, Arántegui, Alcalá Zamora o Cipolla; Cfr. bibliografía final

31 Se tiene constancia de piezas fundidas para el Emperador Carlos desde el año 1516. El aumento de la artillería de bronce fue progresivo durante las dos centurias siguientes.

32 Ver los trabajos de Cipolla, Cañones y Velas, pág. 31; Sánchez Gómez, De Minería, cap. II y cap. IV; Archivo General de Simancas (AGS), Guerra Antigua, leg. 1-82.

33 La escasez de artillería en los Ejércitos Reales españoles y la exasperación de la Corona por conseguir fundirla o comprarla era un hecho habitual. Igualmente en la Armada y en los buques de Indias. El problema radicaba en la escasez que había de maestros fundidores especializados en fundir cañones. En 1547 Felipe II mandó traer a España fundidores de cañones y en 1590 el Capitán General de la Artillería se quejaba de que los fundidores «se iban acabando pues no tenían generalmente dónde trabajan, y cinco años más tarde Lázaro de la Isla lo criticaba en la introducción de su tratado: «Y viendo la falta que en estos reinos había de artilleros, pues siempre que Su Magestad quería hacer alguna empresa, se embiava en Alemaña y otras partes, para tenerlos, me ofrecí a su Supremo Consejo de Guerra, de tener escuela de este arte...». Breve Tratado de Artillería y fundición della y artificios de fuego. 
A lo largo de la segunda mitad de siglo la supremacía de la artillería de bronce resultaba abrumadora debido al alto grado de perfección alcanzado por los maestros fundidores ${ }^{34}$, aunque ya desde esa misma fecha se había empezado a introducir de forma paulatina la de hierro colado, procedente en un principio sobre todo de Inglaterra, que si bien todavía no era tan fácil de fundir como la de bronce, sí que era de menor coste que ésta y más rápida y barata que la de forja. Para entonces, el hierro forjado aplicado a la artillería estaba completamente anticuado ${ }^{35}$.

En palabras de Carrasco, «el advenimiento de la artillería de bronce y después el de la de hierro colado, detuvieron los progresos de la de hierro batido y acabaron por desterrarla enteramente» ${ }^{36}$. Los altos hornos establecidos en el norte de España en la segunda década del siglo XVII con el fin de fundir el hierro pusieron punto y final a la forja de cañones. Se puede decir que en España no se volvió a forjar artillería hasta finales del siglo XVIII y esto únicamente casi como capricho ${ }^{37}$.

Es en este contexto en el que hay que situar los dos cañones de Cristóbal Frisleva, lejos ya de la tosquedad de las primeras piezas forjadas y reforzadas con duelas, fabricados ambos en pleno apogeo de la artillería fundida en bronce.

No se conoce pieza de Cristóbal Frisleva o atribuida a él fundida en bronce; todas las que han llegado hasta hoy fueron forjadas en hierro ${ }^{38}$. Esto no impide que no pudiese aparecer en el futuro alguna obra suya realizada con distinto material, pero hoy por hoy los hechos son indiscutibles.

Martínez de Espinar y otros autores clásicos españoles, ${ }^{39}$ dejan bien claro que el mejor metal para la fabricación de las armas de fuego pequeñas y medianas es el hierro, sirviéndo el bronce únicamente de forma válida para la elaboración de grandes piezas de artillería, esto es, grandes cañones ${ }^{40}$.

34 G. Agrícola, considerado el padre de la mineralogía moderna, lo anunciaba ya en su obra. De Re Metallica (1546; publicada póstumamente diez años después): «Como hoy en día se fabrican muy pocos mosquetones de hierro y los grandes nunca se hacen a base de este metal, sino a base de la mezcla de cobre y estaño...»

35 Collado (Plática Manual de Artilleria) dice a propósito de las Lombardas que eran «unas piezas antiguas de hierro forjado que ya estaban abandonadas usándose tan sólo para salvas de regocijo y habia que andar con cuidado por que solía saltar el másculo en el disparo a pesar de la cuña». En la expedición que mandó Felipe II a las Azores en junio de 1583 figuraban un total de 562 piezas de bronce y 122 de hierro colado en un total de 98 buques; ninguna de hierro forjado. Bernardino de Escalante, Diálogos del Arte Militar, pág. 173 r. En 1639 la armada de Oquendo con destino a los Países Bajos llevaba ya 270 piezas de bronce frente a 265 de hierro colado; y de los aproximadamente diez mil cañones con que contaba la Armada en 1793, sólo veinticinco eran de bronce. Citado por Sánchez Gómez, Op. cit., pp. 126 y 129. Para los primeros intentos de establecer fundiciones de hierro en España y los problemas derivados de ello, ver: «La fundición de artillería en Guipúzcoa en el siglo XVI», comunicación presentada por Ignacio $\mathrm{M}^{\mathrm{a}}$ Carrión Arregui en el 25th Symposium of the International Committee for the History of Technology, 18-22 agosto 1998, Almada/Lisboa, Portugal.

36 A. Carrasco, «Artillería de Hierro». Memorial de Artillería, vol. XIX, pág. 605.

37 El inventario de la Real Armería de 1793 cita, junto con el Frisleva de 1565, seis cañones más de hierro batido hechos en 1773 y 1791. Estos serán los últimos vestigios de cañones de hierro batido hasta que por razones más perentorias, se vuelvan a forjar cañoncitos de duelas durante las guerras carlistas del siglo XIX. En cualquier caso, ambos ejemplos no son comparables a los cañones de hierro forjado que se vienen aludiendo.

38 Existen en la Real Armería de Madrid dos piezas que han sido atribuidas a Cristóbal Frisleva sin tener una certeza absoluta: un cañón de escopeta de retrocarga ( $\mathrm{n}^{\circ}$ inv. 2534, Catálogo de los objetos..., 1861) y un Pistolete con hacha de armar ( $\mathrm{n}^{\circ}$ inv. K 60, Catálogo histórico descriptivo..., 1898). El cañón de escopeta no se encuentra fechado ni firmado, salvo por la X que lleva como marca sobre la culata. El Pistolete, fechado en 1551, no fue atribuido a Frisleva hasta el catálogo de 1898 y su marca, según Lavin, no puede ser asociada en modo alguno al Maestro. El estilo del Pistolete, a mi entender, es completamente alemán. Ambas piezas fueron tratadas por Lavin junto con el cañón de 1565 (Op. cit., pp. 65, 136 y ss).

39 Véase los tratados de los españoles Collado, Alava y Viamont, Lechuga, Ufano o Firrufino; así mismo las de los italianos al servicio de España, Ruscelli o Cataneo.

40 Martínez de Espinar, Tratado de Ballestería y Montería, pág. 22. Igualmente Escalante de Mendoza, Itinerario de Navegación de los Mares y Tierras Occidentales, pág. 44. 
Si como se ha visto, la artillería de bronce se encontraba en su cenit a mediados de la centuria debido a sus buenas cualidades y bajos costes, ¿por qué entonces forjó Cristóbal Frisleva no sólo uno, sino dos pequeños cañones de hierro?. Una posibilidad es que no supiera controlar los métodos de fundición del bronce, sino que prefiriese batir el hierro con el martillo. El estudio realizado en la Facultad de Ciencias Químicas de la Universidad Complutense de Madrid sobre el proceso de forja del cañón no deja dudas al respecto: Frisleva sabía muy bien el trabajo que estaba realizando, demostrando un conocimiento profundo sobre su arte ${ }^{41}$.

El sistema integral de puntería que lleva el cañón de 1565 y el hecho de llevar incorporado el conjunto cazoleta-cobija, usado en las armas de fuego portátiles precisamente para impedir que la movilidad de la pieza a manos de un solo hombre provocase la caída de la pólvora preparada en el receptáculo al uso, la mencionada cazoleta, hacen pensar que el maestro que la forjó tenía muy presente la elaboración de cañones más pequeños, más portátiles.

Por otra parte se puede apuntar que la línea que presentan ambos cañones es similar a la utilizada desde los orígenes en los cañones de arcabuces y pistolas fabricados en la península, conocidos como cañones «a la española», los cuales combinaban un primer tercio ochavado con otros dos tercios troncocónicos, unidos ambos sectores mediante un filete de anillos concéntricos. Esta característica los vuelve a acercar aún más a los cañones de las armas portátiles.

Realmente nada se sabe acerca de Cristóbal Frisleva. En las referencias que se encuentran en los libros de Martínez de Espinar, Isidro Soler y en los diferentes catálogos de la Real Armería, se le ha considerado siempre como un maestro español que trabajó en Ricla, en las cercanías de Zaragoza. La única información de que se dispone en la actualidad al respecto es la inscripción del cañón de 1565 , pero hay que subrayar el hecho, evidente, de que Frisleva dejó estampado que había hecho ese cañón en Ricla. El cañón de 1557 no menciona el lugar donde se fabricó, impidiendo por lo tanto la confirmación de que Frisleva tuviese «su establecimiento fijo en el mencionado pueblo" ${ }^{42}$. A tenor de esto cabe hacerse la siguiente pregunta: ¿se puede afirmar que Cristóbal Frisleva, también conocido por Cristóbal de Ricla, se avecindó allí tal y como afirma el catálogo de Martínez del Romero, basándose únicamente en el hecho de que aparezca dicho topónimo en el cañón de 1565?. A pesar de que no se puede hacer una afirmación de tal envergadura sin su correspondiente confirmación, hay que tener en cuenta que Ricla está enclavado en una zona que ha sido tradicionalmente un importante centro de producción de armas, tanto de fuego como blancas. Sin ir más lejos, aguas arriba del río que baña el pueblo —el Jalón- se encuentra Castejón de las Armas. En general, toda la sierra del Moncayo se puede englobar en esta zona ${ }^{43}$. No sería de extrañar entonces, que un maestro del arte de forjar cañones se estableciese en un pueblo de una región con tradición armera, con hierro abundante y bañado por un importante río.

41 Según se desprende del informe, el autor dió al ánima el mayor grado de dureza forjándolo a una temperatura entre $800^{\circ}$ y $900^{\circ} \mathrm{C}$. Esta zona no fue sometida a ningún tratamiento térmico posterior para conseguir así un acero muy resistente y duro, capaz de soportar los rozamientos de los proyectiles disparados. La recámara se dejó enfriar al aire para que, intencionadamente, disminuyese su fragilidad sacrificando parte de su dureza (a mayor dureza, mayor fragilidad), ya que las explosiones de la pólvora creaban grandes tensiones sobre su superficie interna. La zona central externa se forjó entre $\operatorname{los} 600^{\circ}$ y $720^{\circ} \mathrm{C}$. Su estructura es más blanda para poder resistir las fatigas de los retrocesos. Los muñones se fabricaron por separado y fueron soldados posteriormente a la caña. Informe Metalúrgico sobre un cañón del siglo XVI propiedad del Museo Naval de Madrid.

42 Catálogo de los objetos..., 1849; pág, 158 del catálogo.

43 Barba ya lo recogía en su Tratado: Buelven los Montes de Orospeda entre Castilla y Aragon, y con tres como atalayas muy asperas, se entremeten entre Turiason, y Bilbilis. De estas ciudades habla Plinio, lib. 34 . cap. 14. «Estos y otros lugares ennobleciò la mas provechosa gloria del hierro, como à Bilbilis en España y à Turiasson». Este entre Numancia y Ebro, oy Tarazona. Bilbilis no es Calatayud, está cerca de alli un quarto de legua, como la celebra su Poeta Marcial, lib. 10. 103. en un Monte, que oy se llama Bambola: corre Salón por su pie, ahora Xalòn (...) De sus aguas tuvieron parte de su fama las espadas Españolas, añade Marcial, lib. 12.18. «Mi Patria amada Bilbili sobervial Con el oro precioso, y con el hierro». Alonso Barba, A.: Arte de los Metales, pág. 216. Ricla apenas dista cuarenta kilómetros de Calatayud. 
Martínez de Espinar ya lo incluyó entre los maestros españoles que trabajaban las armas portátiles, esto es, los Maestros Arcabuceros. En el capítulo catorce de su obra hizo un breve estudio sobre los oficiales que forjaron en España, alemanes, italianos y españoles, especificando en algunos casos sus marcas. Entre los últimos incluyó a la saga de los Marcuarte, venidos a España por iniciativa del Emperador Carlos V. Sigue una escueta anotación: «Maesse Christoval de Ricla labró en Aragón, puso por marca una X» ${ }^{44}$. En 1795 Isidro Soler amplió la información al decir que «Christoval de Ricla» salió de la escuela de Juan Salado. El catálogo de la Real Armería de Martínez del Romero llegó más lejos al asegurar que «En este cañón esta la fecha repetida de 1565 y por ella debemos suponer que Frisleva sería ya hombre entrado en años cuando lo fabricó» ${ }^{45}$.

Lavin citó otra fuente en la que aparecía una pareja de arcabuces asociada a Cristóbal Frisleva. Se trata de la tasación de bienes del Duque de Medinaceli realizada en 1594, de la que existe una copia fragmentada en el Archivo del Palacio Real de Madrid. Dicha copia debió ser transcrita a finales del siglo XIX para apoyar y documentar el catálogo de la Real Armería que realizó don Juan Bautista Crooke y Navarrot. En ella se reflejaron diversos bienes del Duque entre los que había por supuesto armas, figurando entre ellas «Un arcabuz de maese Xpobal de Ricla con un frasco de querno y otro frasquillo $p^{a}$ polborin en doce ducados»; y más abajo «Un arcabuz mas pequeño del dho. maestro con un frasquillo que sirve de llabe dorado y plateado con un cordon leonado en doce ducados» ${ }^{46}$. Pero si una persona no se contenta con la copia y quiere trabajar de forma metódica y seria, debe acudir siempre a las fuentes originales y el original de la copia se encuentra en el Archivo Histórico de Protocolos, en Madrid. Lo que se lee en éste es ligeramente diferente: «En el dicho dia se remato por el dicho artiaga un arcabuz de maese Xpobal de rueda. con un frasquillo que sirbe de llabe dorado y plateado en doce ducados»; y en la siguiente entrada: «Otro arcabuz mas largo con un frasco pequeño y otro para polborin (por) el dicho artiaga en otros doce duca$d o s »{ }^{47}$ Evidentemente ese no fue el día del copista. Pero para hacer honor a la verdad, hay que señalar que la palabra clave, Rueda o Ricla, no está del todo clara. El texto fue redactado con escritura gótica cursiva procesal encadenada, ya de por sí complicada de leer. La caligrafía de la palabra rueda es fácil de confundir con la de ricla en cuanto la mano del amanuense no tenga excesivo cuidado al escribirla. El hecho, fundamental e innegable, de que el resto de ambas frases tengan tantos errores de transcripción entre el original y la copia, unido a la forma de redactar el documento, en el cual, a la hora de reflejar el fabricante o constructor del resto de las piezas que aparecen en la tasación de bienes del Duque, se les nombre con el título de maestro seguido del nombre de pila ${ }^{48}$, hace inclinar ligeramente el platillo de la balanza hacia la opción de rueda ${ }^{49}$.

En cualquier caso, Lavin trabajó sin lugar a dudas con la copia de Palacio, en donde la atribución de la autoría de los arcabuces a Cristóbal de Ricla era innegable y le sirvió para prolongar la actividad profesional de Frisleva hasta finales del siglo XVI ${ }^{50}$, cuando en reali-

44 Espinar, Op. cit., pág. 42 r.

45 Catálogo de los objetos..., 1849; pág. 103 del apéndice.

46 «Tasación de los objetos de plata dorada, tapices, alfombras, armas y otros bienes quedados al fallecimiento de Dn. Juan Luis de la Cerda, Duque de Medinaceli, ante Dn. Juan del Campillo, escribano que ha sido de Madrid, en septiembre de 1594». Archivo General de Palacio, Caja 322, Legajo 11.

47 «Tasación de bienes del Duque de Medinaceli». Archivo Histórico de Protocolos, registro 628, folio 830.

48 De esta forma por ejemplo, en la anotación anterior a la del arcabuz en cuestión se hace referencia a una ballesta «de maese frc ${ }^{\circ} »$.

49 Los expertos a los que se consultó para su verificación (uno de la facultad de Geografía e Historia de la Universidad Complutense de Madrid; otro del Archivo General de Simancas, Valladolid; y dos del Archivo Histórico de Protocolos de Madrid), no coincidieron en sus conclusiones: dos estuvieron a favor de la opción de Rueda, otro por la de Ricla y otro por ninguna de ambas.

50 Lavin, Op. cit., pág. 136. 
dad en el manuscrito no queda claro que el arcabuz sea de Xpobal de ricla, sino mas bien que el arcabuz (de maese Xpobal) es de rueda. Para confirmar la relación de esta última palabra con el resto de la anotación que sigue, sirven las propias palabras de Lavin, quien inconscientemente daba la solución: «Among the numerous accessories required for the use and maintenance of a wheel-lock, the most essential was the spanner. Like the lock, this also was called llave and to avoid confusion was often designated the «llave for arming (llave de armar)». In Spain as elsewhere, it was sometimes combined with a priming flask (frasquillo) .... ${ }^{51}$. Es decir, quedan así asociados el arcabuz de rueda con el frasquillo que sirve, además, de «llave» para hacer girar el mecanismo de ignición del arma.

Quizás el maese Xpobal fuese en verdad Cristóbal Frisleva, pero desde luego no se tiene constancia absolutamente segura hoy en día de que se le conociese por el topónimo del pueblo aragonés a finales del siglo XVI. Si así fuera, significaría que Cristóbal Frisleva era conocidísimo en su tiempo por la cantidad y calidad de sus obras, habiendo tenido que llegar alguna más hasta nosotros junto con más referencias sobre su autor. Y de momento no ha ocurrido ninguna de ambas cosas. Significaría también que Frisleva, si no había nacido en Ricla, debería haberse asentado allí con bastante antelación para que su fama fuera acompañada del topónimo.

Lavin sugirió que su origen era alemán, con lo que el apellido por el que le conocemos habría sido castellanizado ${ }^{52}$. Ahora bien, esto plantea dos cuestiones importantes. Saber si el apellido fue castellanizado y, si así fue, en cuánto tiempo se produjo. Ambas cuestiones son hoy por hoy imposibles de averiguar. No obstante, se pueden apuntar algunas consideraciones. En primer lugar hay que volver a las inscripciones que portan ambos cañones. Recuérdese que en el cañón de 1565 aparece marcado dos veces el nombre del autor. En la inscripción que porta sobre la recámara aparece el nombre seguido del apellido Frisleva, pero nótese que entre las letras $\mathrm{R}$ e I de esta última palabra, falta claramente otra letra que al parecer nunca fue estampada, quedando sin embargo el hueco perfecto para ella. En el escudete entre los muñones lleva el mismo nombre junto al apellido Freisleva. ${ }^{53}$ Esta diferencia en una letra puede apuntar en la dirección que señaló Lavin y puede dar a entender el por qué de la mala grafía en el cañón de 1557, ya que el troquelar el apellido completo hubiese sido harto difícil dado el espacio disponible. Igualmente pudo ocurrir con la palabra Aníbal, que es la única escrita en castellano en una inscripción en la que reina el latín, a diferencia de la de 1565 . El abreviar la palabra no implicaba ninguna confusión al respecto, pero también pudiera ocurrir que efectivamente fuera de origen alemán, o centroeuropeo, y no tuviera todavía el conocimiento adecuado del idioma castellano y preferir así el latín, al contrario que ocho años después, cuando escribe la mayoría de la leyenda en castellano.

Si Cristóbal Frisleva no nació realmente en España y castellanizó su nombre, habría que hacerse de nuevo otra pregunta: ¿cuánto tiempo pasó desde la llegada de Frisleva a España hasta la efectiva transformación del apellido?. Esto es igualmente imposible de dilucidar. Sin embargo tenemos un ejemplo similar en el apellido de los Marcuarte con el que se puede hacer una comparación. Lavin dejó claro que la llegada de la saga de armeros alemanes a España, se tuvo que producir entre finales de la década de 1560 y el principio de la siguiente.

51 Lavin, Op. cit., pág. 68.

52 «Nothing is known of the origin of Cristóbal Frisleva of Ricla. However, his surname was undoubtedly originally the German Freiersleben, which in middle High German would probably have been Frislëben». Lavin, Op. cit., pág. 147, nota 17. El autor no indicó nada más al respecto. Curiosamente, Joseph Conrad cuando escribió El Corazón de las Tinieblas (1902), cruzó en el camino de Marlow en busca del agente comercial Kurtz, perdido en el interior de Africa, a un hombre llamado Fresleven. El personaje estaba basado en la vida real en un capitán danés llamado Freiesleben. El apellido es indudablemente el mismo.

53 Es curioso comprobar cómo en los catálogos de la Real Armería de 1849 y 1861, sólo aparece recogida una versión del apellido, Frisleva. 
Se conserva una carta de Simón Marcuarte «el Viejo» con fecha de 30 de mayo de 1572, en la que este firma como Sigmund Marquardt; y otra, fechada trece años después, en la que ya aparece como Simón Marquarte. ${ }^{54}$ Es decir, que el tiempo que tardó en este caso el apellido en castellanizarse podría ser alrededor de diez años. Esto no quiere decir que sea una regla sistemática y exacta, pero sí que se puede tomar como ejemplo válido para un «caso modelo» a mediados del siglo XVI. Ya que el cañón del Museo Naval está fechado en 1557 , ¿en que fecha habría que situar la llegada de Cristóbal Frisleva? Como mínimo unos pocos años antes, a principios de la década.

Esto conduce a un hecho muy importante. Sea como fuere, la existencia del cañón del Museo Naval prueba que Frisleva trabajó en España antes de la llegada de los Marcuarte, e incluso antes quizás de que ellos mismos comenzasen a trabajar en el oficio, ya que para 1555, muerto ya su padre, los hermanos Simón y Pedro pasaron a ser custodiados por unos tutores responsables de su educación ${ }^{55}$ y puestos a trabajar luego como aprendices de otro armero en Aubsburgo. Cuando Frisleva forjó su cañón en 1557 los hermanos Marcuarte debían rondar la edad de doce años. Esto confirma la existencia en España de una escuela de alta calidad (al margen de la vizcaína, de carácter más militar durante la primera mitad del siglo XVI) ${ }^{56}$, anterior a la llegada de los armeros de la familia alemana en contra de los señalado por Espinar ${ }^{57}$ y reafirmado por Soler, quien sitúa en los orígenes de la tradición armera española a los mencionados Marcuarte ${ }^{58}$.

Por otra parte corrige también la «escuela» que empezaron a formar los alemanes ya que, según Soler, Simón Marcuarte enseñó a Juan Salado y éste tomó como alumnos a Pedro Palacios, Juan Sánchez de Mirueña y al mismísimo Cristóbal Frisleva ${ }^{59}$. Lavin ya criticó este error $^{60}$ basándose en la fecha del cañón de 1565 , por lo que el cañón de 1557 vuelve a rebajar cronológicamente la actividad profesional de Frisleva.

\section{CONCLUSIONES}

La principal finalidad de estas páginas ha sido dar a conocer el cañón hecho por Cristóbal Frisleva en el año 1557 y conservado hoy en día en el Museo Naval de Madrid. Por la

54 «I does show that by 1585, the Augsburger Siegmund Marquart had become the madrileño Simón Marquarte». Lavin, Op. cit., pp. 72-75.

55 «Lenhart Maier, costurero, y Bernhardt Stahel, plomero». Ibid., pág. 72.

56 Sobre el tema ver AGS, Guerra Antigua, Legajo 1-83, y las obras de Arántegui, Carrasco y en especial Lavin, Op. cit., pág. 93, así como el apéndice documental que incluye Ramiro Larrañaga en su obra Síntesis Histórica de la Armería vasca, San Sebastián, 1981.

57 «Los primeros cañones que se conocieron por buenos en España, fueron de Alemania ...» Martínez de Espinar, Op. cit., pág. $42 \mathrm{r}$.

58 Isidro Soler, Op., cit., pp. 38-41. La confusión originada con la obra de Isidro Soler se arrastra hasta principios del s. XX. De esta forma en los Manuales Gallach para armas de caza (editados hacia 1905), se lee: (Carlos V) «hizo venir de Alemania dos de los mejores maestros, los famosos arcabuceros Pedro Maese y Simón Marcuarte (...). Estos fueron los patriarcas de la brillante serie de artifices que crearon una industria de justa y merecida fama en todo el mundo, especialmente por la exquisita calidad de los cañones de escopeta y pistola, muy superiores á cuanto en aquella época se hacía fuera de España. (...). Descuella sobre todos los discípulos de estos famosos arcabuceros, Cristóbal Frisleba...” J. Génova e Y., Manuales Gallach, pp. 11-13. De igual forma en la literatura extranjera, como por ejemplo en la italiana: «Frisleva (Cristobal). Archibugiere spagnuolo del secolo XVI. Fu della scuola dei Marcuate e si ritrasse a Ricla, sobborgo di Saragozza (1565)». La fecha recogida es significativa. Gelli, I.: Guida del raccoglitore e dell'amatore di Armi Antiche. Por otro lado, la monumental Guide $d u$ Stockel da igualmente como fecha de actividad laboral de Frisleva la marcada sobre el cañón del Museo del Ejército, Der Neue Stockel, T. I, pág. 403.

59 Ibid, pp. 40-42.

60 Para ver todos los detalles de los errores que contiene Soler, véase las pp. 26 y 27, así como el cap. V1, The Remaining Smiths, de la obra de Lavin. 
documentación encontrada hasta la fecha, el cañón fue hallado durante las excavaciones realizadas en el arsenal de Cartagena durante los últimos siete años del siglo XVIII y posteriormente fué guardado en los almacenes por un tiempo indefinido. Gracias a la formación de un Museo Naval en la capital de España, se reclamaron piezas al Arsenal de Cartagena para que formasen las futuras colecciones, siguiendo la política de acrecentamiento de los fondos, y de esta forma el cañón fue enviado a Madrid a mediados de 1845, quedando así reflejado en el primer inventario del Museo Naval dos años después. Este cañón de hierro forjado ha estado, por lo tanto, en el orígen de las colecciones del Museo desde la sede de la Casa del Platero, donde quizás estuvo expuesto por vez primera.

Las únicas referencias que se tienen de su autor están basadas documentalmente sobre las que Martínez de Espinar escribió acerca de los más famosos arcabuceros que desde los orígenes de este arte habían trabajado en España. Espinar incluyó entre ellos a Frisleva como discípulo de una «escuela» cuyos orígenes se remontan a la llegada de maestros alemanes traídos a la península por el Emperador. Así mismo, se citaba a Frisleva avecindado en un pueblo aragonés, Ricla, un dato que transmitía la leyenda de la única inscripción que se tenía de él hasta la fecha: un cañón de pequeño calibre de hierro, forjado en 1565. Este era el único documento material que justificaba, y sigue justificando hasta hoy, tal afirmación. Es muy probable, en efecto, que Frisleva se asentara en tierras aragonesas y estableciera allí su negocio, ya que desde tiempos romanos era una zona armera importante debido a la abundancia de mineral de hierro. Esto sin embargo, aún no ha podido ser confirmado. La leyenda del cañón de 1565 ha tenido mucho peso para una persona que no dejó tras de sí ningún rastro. En la documentación del testamento del Duque de Medinaceli ha quedado demostrado a su vez que la alusión a Frisleva, conocido como Cristóbal de Ricla, es cuando menos insegura y, por lo tanto, tampoco se puede afirmar que fuese conocido por el topónimo de dicho lugar a finales del siglo XVI. Otros autores como Isidro Soler, consolidaron el error y aumentaron el mito, arrastrándolo en la historiografía hasta nuestros días.

Sin embargo, la aparición del cañón de 1557 ha abierto nuevas perspectivas para el estudio, no sólo de su autor, sino del arte de la forja de armas de fuego en España. La fecha que porta el cañón junto al nombre de su autor están fuera de toda duda y demuestran que Frisleva, al margen de si era o no nacido en tierras españolas, trabajó en los años previos a la llegada de los famosos Marcuarte, considerados los padres de la arcabucería española. Anteriormente al conocimiento del cañón de 1557 se le atribuía una vida laboral comprendida entre 1560 y 1594 aproximadamente, basándose en el cañón de 1565, única referencia fiable que se tenía hasta ahora para poder datar su producción, cuando en realidad se sabe con absoluta seguridad que trabajó, como mínimo, durante los años que median entre la realización de ambos cañones.

Por otra parte, el cañón de 1557 es importantísimo ya que siendo anterior al de 1565 , demuestra que éste no es si no prácticamente un calco de áquel. Las razones que tuvo Frisleva para realizar dos piezas iguales, sólo él las conocía. Quizás no quedó contento con la primera realización y trabajó una segunda más perfecta y cuidada; pero la voluntad de su autor es francamente clara: estructuralmente el segundo cañón es exactamente igual al primero y aunque la decoración varíe mínimamente, el diseño a la hora de plasmarla, sobre un fondo punteado, en fajas de las mismas longitudes y colocadas en los mismos lugares y del mismo modo, también se repite. El hecho de que este segundo cañón acabara en una colección Real y su antecesor fuera rescatado en las excavaciones de un puerto con claro carácter militar, dicen mucho de los caminos que ambos cañones tomaron.

Estas dos piezas son únicas en el sentido de que son las primeras piezas de artillería conservadas que nos consta fueron hechas por un maestro de armas portátiles. No se conoce ningún otro arcabucero, mencionado o no por Espinar o Soler, del que se tenga noticia y menos aún piezas tangibles, que forjara cañones de artillería ligera. La forma de ambos cañones 
es totalmente a la española, hecho que los acerca a los cañones de arcabuces y mosquetes; por otro lado, ¿quién iba a poner una mira tan precisa en una pieza de artillería, sino un maestro acostumbrado al detalle por lo pequeño?

Para finalizar quedaría una última pregunta por resolver: saber si Cristóbal Frisleva bautizó su primer cañón con el nombre de Aníbal sabiendo que iba destinado a Cartagena, la Carthago Nova del Imperio Púnico que fue tomada por su eterno rival, Escipión el Africano en el 209 a.c., o fué una pura coincidencia. Eso es algo que el Maestro se llevó consigo a los Cielos. O a los Infiernos.

\section{AGRADECIMIENTOS}

Quisiera agradecer la ayuda prestada para la redacción de este artículo a las siguientes personas: al almirante D. José Ignacio González-Aller Hierro, director del Museo Naval de Madrid; al Dr. D. Alvaro Soler del Campo, conservador de la Real Armería de Madrid; al Dr. D. Antonio José Criado y Dr. D. Juan Antonio Martínez, profesores del Departamento de Ciencia de los Materiales e Ingeniería Metalúrgica, de la Facultad de Ciencias Químicas de la Universidad Complutense de Madrid, así como a Victoria Mollón Sánchez y Angel García Abajo, de su equipo; al Dr. D. Javier del Hoyo, profesor del Departamento de Filología Clásica de la Facultad de Filosofía y Letras de la Universidad Autónoma de Madrid; a D. José Borja Pérez y al capitán de infantería D. José A. González Suárez, ambos del Museo del Ejército de Madrid; a los fotógrafos del Museo del Ejército y del Museo Naval respectivamente, Sonia Bergmann y Juan Antonio Clemente; y por último, pero no menos importante, a Mónica Solís Servert.

Francisco Javier LóPEz Martín

Museo Naval. C/ Montalbán, 2 - 28071 Madrid

\section{FUENTES MANUSCRITAS}

Archivo General de la Marina, Don Alvaro de Bazán: Arsenales-Correspondencia-Subinspección, legajos 3665 y 3666.

Archivo General de Palacio, Cajas 322 y 15826.

Archivo General de Simancas, Guerra Antigua, Legajos 1-82, 83.

Archivo Histórico de Protocolos, Registro, 628.

Archivo Museo Naval, Asuntos Particulares, 1797-1850.

Archivo Museo Naval, Sección Dibujos, P4-18.

Inventario General del Museo Naval. Madrid, 1847.

Memorial de la Santa Iglesia de Toledo, suplicando aumentar el armamento naval para contrarrestar el poderío de Africa. Biblioteca Nacional de Madrid, V. C-52-23.

\section{FUENTES IMPRESAS}

ABADIA, I.: Resumen sacado del inventario general histórico de los arneses antiguos, armas blancas y de fuego con otros efectos de la Real Armería del Rey Nuestro Señor. Madrid, 1793.

Alava Y Viamont, D.: El perfecto Capitan, instruido en la disciplina Militar y nueva ciencia de la Artillería. Madrid, 1590.

CAlvete de Estrella, J. C.: El felicissimo Viaje del Muy Alto y muy Poderoso Principe don Felipe. Amberes, 1552.

Collado, L.: Platica manual de artilleria. Milán, 1592. 
ESCALANTE, B. de: Dialogos de Arte Militar. Sevilla, 1583.

ESCALANTE DE MENDOZA, J.: Itinerario de Navegación de los Mares y Tierras Occidentales. 1575.

ESTADOS GENERALES DE LA ARMAdA, Años 1785 a 1800.

FirRuFIno, J. C.: El perfecto Artillero. Theorica y Practica. Milán, 1626.

LAZARO DE LA ISLA, G.: Breve Tratado de Artillería y fundicion della y artificios de fuego. Valladolid, 1595.

LECHUGA, C.: Discurso en que se trata de artilleria y de todo lo necesario a ella. Milán, 1611.

Martinez De EsPinAR, A.: Tratado de Ballestería y Montería. Madrid, 1644.

SOLER, I.: Compendio Histórico de los Arcabuceros de Madrid. Madrid, 1795.

\section{BIBLIOGRAFÍA}

Alcala Zamora y QueIPo De Llano, J.: «Velas y cañones en la política septentrional de Felipe $I I_{\gg}$. Cuadernos de Historia Jeronimo Zurita, $n^{\circ} 23$ y 24.

Alonso Barba, A.: Arte de los metales. Madrid, (s. f.) (facsímil, Consejo Superior de Investigaciones Científicas, 1992).

ARANTEGUI Y SANZ, J.: La Artillería Española en los siglos XIV y XV. Madrid, 1887 (vol. I) y 1891 (vol. II).

CARRASCO, A.: «Apuntes para la historia de la fundición de artillería de bronce». Memorial de Artillería. Madrid, 1887. vols. XV y XVI.

CARRASCO, A.: «Apuntes para la historia de la fabricación de artillería y proyectiles de hierro». Memorial de Artillería. Madrid, 1889. vol. XIX.

CARRASCO, A.: Antiguos inventores de Artillería. Madrid, 1887.

CATALOGO del Museo Naval. Madrid, 1908.

CATALOGo de los objetos de la Real Armería. Madrid, 1861.

CATALOGO descriptivo de los objetos que contiene el Museo Naval. Madrid, 1853.

CATALOgO general del Museo de Artillería. 4 vols., Madrid, 1914.

CIPOLLA, C.: Cañones y velas en la primera fase de la expansión europea, 1400-1700. Barcelona, 1967.

CONDE VDo. DE VAlEnCia De DON JuAN, (Juan Bautista Crooke y Navarrot): Catálogo históricodescriptivo de la Real Armería de Madrid. Madrid, 1898.

CRIADO PORTAL, A. J. y cols.: Informe Metalúrgico sobre un cañón del siglo XVI propiedad del Museo Naval de Madrid. Facultad de Ciencias Químicas, Universidad Complutense de Madrid, 1998. Comunicación escrita, no publicada.

CHECA, F.: Felipe II Mecenas de las Artes. Madrid, 1993.

FonTANA, J.: La quiebra de la Monarquía Absoluta 1814-1820. Barcelona, 1987.

FRENZEL, E.: Diccionario de Argumentos de la Literatura Universal. Madrid, 1976.

GELLI, I.: Guida del raccoglitore e dell'amatore di Armi Antiche. Milán, 1968.

GonZaleZ-Aller HierRo, J. I.: Catálogo-Guía del Museo Naval de Madrid. Madrid, 1996.

HALE, J. R.: Guerra y Sociedad en la Europa del Renacimiento, 1450-1620. Madrid, 1990.

HEER, E.: Der Neue Stockel. 3 vols., Schwäbisch Hall, 1978.

LARRAÑAGA, R.: Síntesis histórica de la armería vasca, San Sebastián, 1981.

LAVIN, J. D.: A History of Spanish Firearms. Londres, 1965.

Martinez Del Romero, A.: Catálogo de los objetos de la Real Armería. Madrid, 1849.

OLESA MUÑIDO, F.: La organización naval de los Estados Mediterráneos y en especial de España durante los siglos XVI y XVII. Madrid, 1968. 
PUYOL, J.: «Jerónimo Münzer. Viaje por España y Portugal en los años 1494 y 1495». Boletín de la Real Academia de la Historia, Madrid, 1924.

SÁnchez Gómez, I.: De Minería, Metalúrgica y Comercio de Metales. La minería no férrica en el Reino de Castilla. 1450-1610. 2 vols., Salamanca, 1989.

VIGÓN, J.: Historia de la Artillería Española. Madrid, 1947.

\section{ADDENDA}

Tras la finalización de estas páginas, se localizó el documento que refleja la creación del Obrador de Instrumentos Náuticos en el Arsenal de Cartagena. Está fechado en el mes de febrero de 1793, corroborando las ideas expresadas anteriormente. Ya tenemos, por lo tanto, un dato fehaciente que delimita aún más la fecha del hallazgo del cañón de Frisleva.

La transcripción del documento es la siguiente: Ha determinado el Rey q Se haga en ese Arsenal el obrador de Instrumentos Náuticos, en el paraje y forma q tiene propuesto a SM el Inspector General Dn Felix de Texada fiando la Direccion, y economia de este edificio al Sub Insp.or de ese Arsenal, como q es de su Inspeccion dho. Obrador, y debe arreglar su repartim.to, y extension a lo q crea sea neces.o. Aavisolo a VE de Ord. De SM pa que se halle enterado y disponga su cumplimiento en la parte q le corresponda, Dios guarde a VE muchos años. Aranjuez 8 de Febrero de 1793. Valdés. Sr. Capitán General del Departam.to de Cartagena. (MNM, Colección Vargas Ponce, T. XXXIX, Doc. 272, Fol. 291. Ms. 70). 